\title{
Pengaruh Sport Massage Terhadap Penurunan Denyut Nadi Recovery Atlet Futsal IKIP Mataram Tahun 2018
}

\author{
Muhamad Hafizudin, Subakti, Andi Gilang Permadi. \\ Mahasiswa Pendidikan Olahraga Dan Kesehatan, FPOK IKIP Mataram \\ Dosen Pendidikan Olahraga Dan Kesehatan, FPOK IKIP Mataram \\ Email : muhammadhafizudin91@ gmail.com
}

\begin{abstract}
Abstrak: Penelitian ini dilator belakangi oleh atlet futsal IKIP Mataram seringkali cepat merasa lelah, rawan cedera, dan sulit memulihkan denyut nadi. Adapun yang menjadi masalah dalam penelitian ini adalah "apakah ada pengaruh sport massage terhadap penurunan denyut nadi recovery atlet futsl IKIP Mataram tahun 2018. Penelitian ini bertujuan untuk mengetahui ada atau tidaknya pengaruh sport massage terhadap penurunan denyut nadi recovery atlet futsal IKIP Mataram tahun 2018. Penelitian ini merupakan penelitian eksperimen. Penelitian ini menggunakan dua variable yang terdiri dari satu variable bebas (sport massage) dan satu variable terikat yaitu denyut nadi recovery. Populasi yang digunakan dalam penelitian ini adalah seluruh atlet futsal IKIP Mataram tahun 2018, sebanyak 9 pemain. Tehniksamplingyangdigunakanyaitu tehnik studi populasi. Teknik pengambilan data menggunakan metode perbuatan yaitu test dan pengukuran dengan instrument ttehnik phalpase. Teknik analisis data menggunakan analisis uji t dengan taraf signifikan $5 \%$. Karena $t$ hitung $>\mathrm{t}$ table $(4,603>1,833)$ maka hasil penelitian ini menunjukan bahwa ada pengaruh sport massage terhadap penurunan denyut nadi recovery atlet futsal IKIP Mataram tahun 2018.
\end{abstract}

Kata Kunci :Sport Massage, Denyut Nadi Recovery, dan Atlet Futsal

\section{PENDAHULUAN}

Aktivitas olahraga yang dilakukan bertujuan untuk meningkatkan kualitas fisik sumber daya manusia, apabila dilakukan secara benar dan teratur. Setalah melakukan aktivitas olahraga kita sering merasa lelah, otot pegal dan sakit. Untuk mengatasi rasa sakit atau pegal tersebut, tubuh perlu pemulihan yang cukup sehingga menjadi segar kembali. Aktivitas olahraga futsal merupakan permainan bola yang dimainkan oleh dua tim, yang masing-masing beranggotakan lima orang. Selain lima pemain utama, setiap regu juga diizinkan mempunyai pemain cadangan. Tipe kondisi fisik permainan ini tidaklah sama dengan permainan sepak bola dikarenakan permainan futsal mempunyai karakteristik permainan yang cepat antara posisi bertahan dan menyerang, dalam waktu bermain $2 \times 15$ menit permainan tidak akan berhenti berlari, bergerak dan bertukar posisi. (Andi Anshari Bausad, Arif Yanuar Musrifin, 2016: 229). Untuk mendapatkan pemulihan yang baik pemin futsal IKIP Mataram harus mendapatkan treattmen massage pada saat selesai pertandingan, sehingga tubuh menjadi pulih, bugar, dan denyut nadi menjadi normal kembali untuk mengikuti pertandingan selanjutnya.

Denyut nadi dapat dijadikan tolak ukur untuk kebugaran jasmani pemain futsal. Waktu pulih yang baik adalah dengan jumlah denyut nadi dibawah 100 denyut per menit setelah 5 menit. Dengan demikian maka waktu pemulihan asal dapat digunakan untuk melihat tingkat kemajuan latihan yang sudah dilakukan. Sport massage adalah manipulasi dengan menggunakan tangan, untuk menstimulasi, merelaksasi serta mengurangi ketegangan, dan kelelahan pada atlet maupun pemain yang telah melakukan kegiatan olahraga. Sport massage dibutuhkan bukan hanya oleh atlet (professional dan amatir) tapi juga oleh mereka yang memiliki aktivitasnonolahraga, tetapi banyak memforsir kerja tubuh, misalnya ibu yang sering menggendong anak yang masih kecil dan pekerja kantor yang sering kali duduk didepan komputer dalam waktu yang lama. Sport massage berpengaruh melancarkan peredaran darah, massage merupakan manipulasi dari struktur jaringan lunak yang diterapkan pada tubuh manusia 
untukmenimbulkan rasatenang, nyaman, rileks,dan mengurangi rasasakit.

Denyutnadi sendiri menurut Thomson, (2008:28) adalah jumlah waktu jantung berkontraksi, biasanya dinyatakan dalamjangka waktu yang 1 menit dan dilaporkan sebagai denyut per menit (bpm). Sedangkan Kusnanik, dkk. (2011:107) detak jantung atau juga dikenal dengan denyut nadi adalah tanda penting dalam bidang medis yang bermanfaat untuk mengevaluasi dengan cepat kesehatan atau mengetahui kebugaran seseorang secara umum.

Dengan dasar-dasar teori yang telah diuraikan di atas, maka timbul keinginan peneliti untuk menguji teori tentang Pengaruh Latihan Sport Massage Terhadap Penurunan Denyut Nadi Recovery Atlet Futsal Ikip Mataram 2018

Maka tujuan yang ingin tercapai dalam penelitian ini adalah sebagai berikut: "Untuk mengetahui ada atau tidaknya pengaruh sport massage terhadap penurunan denyut nadi recovery pada atlet futsal IKIP Mataram tahun 2018.

Beberapa manfaat Penelitian ini :

1. Manfaat Teoritis

a. Diharapkan informasi yang didapat bermanfaat bagi keilmuan di bidang olahraga khususnya cabor Futsal untuk dapat mengembangkan dan meningkatkan kualitas Fisik seorang pemain Futsal

b. Hasil penelitian ini diharapkan dapat memotivasi peneliti lain untuk mengadakan penelitian lebih lanjut tentang hal-hal yang belum terungkap dalam penelitian ini.

2. Manfaat Praktis

Hasil penelitian ini diharapkan dapat berguna bagi para atlet dalam menyusun program latihan tambahan sebelum dan sesudah latihan untuk meningkatkan perestasi atlet itu sendiri.

Futsal

Futsal adalah perminan bola yang dimainkan oleh dua regu dengan satu reguny sebnyk 5 orang. Tujuan permainan ini, sama dengan permainan sepak bola, yitu memasukkan bola sebanyak-banyaknya kegawang lawan. Lapangan futsal dibtasi istilah futsal garis. Jadi istilah futsal pada dasarnya dari Spanyol dan Portugis "Futbal
Salon" atu bahasa Spanyol "Futbal Sala", yng diterjemahkan secara harafih berarti“" Sepak bola dalam ruangan. (Soemardiawan: 2016).

\section{METODE PENILITIAN}

Rancangan penelitian merupakan sebuah rancangan bagaimana suatu penelitian akandilakukanDalam penelitian eksperimen ada perlakuan (treatment), sedangkan dalam penelitian naturalistik tidak ada perlakuan. Dengan demikian metode penelitian eksperimen dapat diartikan sebagai metode penelitian yang digunakan untuk mencari pengaruh perlakuan tertentu terhadap yang lain dalam kondisi yang terkendalikan (Sugiyono, 2013: 72).Desain penelitian merupakan sebuah rancangan bagaimana suatu penelitian akan dilakukan. Rancangan penelitian yang dirumuskan dalam sebuah desain penelitian biasanya dijelaskan bagaimana data/informasi dikumpulkan, mekanisme kontrol dilakukan, dan upaya meningkatkan validitas penelitian.

Adapun rancangan penelitian yang digunakan adalah $t$ test Desain penelitianyangdigunakanpada

penelitianiniadalah"one group pretestposttest design".

Desain tersebut digambarkan sebagai berikut :

\section{$\mathrm{T} 1 \quad \mathrm{X} \quad \mathrm{T} 2$}

Keterangan :

T1 : Pree-test ( Tes awal Smash)

$\mathrm{X}$ : Perlakuan Sport Massage

T2 :Post-Test ( Tes akhir )

Populasi adalah generalisasi yang terdiri atas obyek dan subyek yang mempunyai kuantitas dan karakteristik tertentu yang ditetapkan oleh peneliti untuk dipelajari dan kemudian ditarik kesimpulannya (Sugiyono, 2000: 57). Sedangkan Riduwan, (2002: 3) mengatakan bahwa "populasi adalah keseluruhan dari karakteristik atau unit hasil pengukuran yang menjadi objek penelitian". Dari beberapa pendapat di atas dapat ditarik kesimpulan bahwa populasi merupakan objek atau subyek yang berada pada suatu wilayah dan syarat-syarat tertentu berkaitan dengan masalah penelitian. 
Dalam penelitian ini yang menjadi populasinya Atlet Futsal IKIP Mataram 2018 yang berjumlah 9 Atlet.

Pengumpulan data merupakan upaya sistematis untuk memperoleh informasi mengenai obyek penelitian. Disebut juga upaya sistematis, sebab pelaksanaan pengumpulan data dilaksanakan dengan mengikuti langkah-langkah tertentu yang kalau tidak dilakukan secara seksama akan menimbulkan bias sehingga akhir peneliti tidak mampu menjawab masalah penelitian dengan seksama. Disebut pula dalam batasan bahwa yang ingin diperoleh adalah semua informasi mengenai obyek penelitian dan settingnya (Sandjaja dan Heriyanto, 2006:183).

Instrumen dalam penelitian ini adalah instrument Tes Smash Bulu tangkis.

Instrumen penelitian merupakan alat yang digunakan untuk mengukur variabel dalam rangka mengumpulkan data (Sandjaja dan Heriyanto, 2006:141).

Instrument yang digunakan dalam penelitian ini yaitu teknik Phalpase. Teknik Phalpase yaitu cara menghitung denyut nadi yang paling mudah dan sering dilakukan adalah jari telunjuk, jari manis, dan ibu jari tangan kanan meraba denyut nadi radialis kiri tengah (pergelangan tangan kiri) selama 10 detik dan jumlahnya dikalikan 6 , berarti denyut nadi 1 menit.

Dalam penelitian kuantitatif, analisis data merupakan kegiatan setelah data dari responden atau sumber data lain yang terkumpul. Kegiatan dalam analisis data adalah mengelompokkan data berdasarkan variabel dan jenis responden, menyajikan data setiap variabel yang diteliti, melakukan perhitungan untuk menguji hipotesis. Metode yang digunakan dalam penelitian ini adalah metode eksperimen yang menggunakan pretest dan posttest maka untuk analisa data menggunakan rumus t-test untuk sampel sejenis.

t-testadalah teknik statistik yang digunakan untuk menguji signifikansi perbedaan dua buah mean yang berasal dari dua buah distribusi.

Untuk keperluan tersebut penulis menggunakan rumus "t-tes" dengan penjabaran sebagi berikut :

$$
t=\frac{\sum \mathrm{D}}{\frac{\sqrt{N \cdot \sum D^{2}-\left(\sum \mathrm{D}\right)^{2}}}{(\mathrm{~N}-1)}}
$$

(Hulfian, 2014: 70)

Keterangan:

$\mathrm{D}=$ Perbedaan setiap pasangan skor (post test-pretest)

$\mathrm{N}$ =Jumlah sampel yang digunakan

\section{HASIL DAN PEMBAHASAN}

Pengambilan Data

Sebagaimana telah dikemukakan dalam BAB sebelumnya bahwa penelitian ini diharapkan pada pencapaian tujuan untuk mengetahui "Apakah ada pengaruh sport massage terhadap penurunan denyut nadi recovery atlet futsal Ikip Mataram 2018".

Untuk itu peneliti telah melaksanakan penelitian guna mendapatkan data tentang kemampuan para atlet tersebut. Peneliti dalam penelitian ini menggunakan dua metode pengumpulan data.

Berikut adalah data table post tes dan pre tes.

\begin{tabular}{|c|c|c|c|c|c|}
\hline \multirow[b]{2}{*}{ No. } & \multirow[b]{2}{*}{ Nama } & \multicolumn{2}{|c|}{ Tes Denuut Nadi } & \multirow[b]{2}{*}{ D } & \multirow[b]{2}{*}{$\mathbf{D}^{2}$} \\
\hline & & $\begin{array}{l}\text { Pre Test } \\
\text { (T1) }\end{array}$ & $\begin{array}{l}\text { Post Test } \\
\text { (T2) }\end{array}$ & & \\
\hline 1. & $\begin{array}{ll}\text { Ahmad } & \text { Lutfi } \\
\text { Zarkasi }\end{array}$ & 108 & 80 & 28 & 784 \\
\hline 2. & $\begin{array}{l}\text { Livan } \\
\text { Pradana }\end{array}$ & 120 & 120 & 0 & 0 \\
\hline 3. & Rio Herwanda & 148 & 116 & 32 & 1024 \\
\hline 4. & Bahtiar Husen & 124 & 84 & 40 & 1600 \\
\hline 5. & Zahroul & 156 & 116 & 40 & 1600 \\
\hline 6. & Asep & 80 & 124 & -44 & 1936 \\
\hline 7. & Bihamdi & 136 & 124 & 12 & 144 \\
\hline 8. & $\begin{array}{ll}\text { Dian } & \text { Pxatama } \\
\text { Putra } & \end{array}$ & 152 & 128 & 24 & 576 \\
\hline 9. & $\begin{array}{l}\begin{array}{l}\text { Loud. Mairur } \\
\text { Hidavat }\end{array} \\
\end{array}$ & 124 & 120 & 4 & 16 \\
\hline \multicolumn{2}{|c|}{ Jumlah } & 1108 & 1052 & 224 & 7680 \\
\hline
\end{tabular}

Setelah mendapatkam nilai t-hitung Hasil perhitungan $t$ berdasarkan rumus diatas adalah t-hitung yaitu 4,603 yang dibandingkan dengan t-tabel pada taraf signifikan $5 \%$ pada derajat kebebasan n-1 (9-1=8 )yaitu 1,860. Jadi, jika dilihat dari analisis data uji-t t-hitung $>t$-tabel $(4,603>1,860)$ maka dapat disimpulkan sport massage memiliki pengaruh yang sangat signifikan terhadap penurunan denyut nadi recovery pada pemain futsal IKIP Mataram tahun 2018.

\section{Pembahasan Hasil Penelitian}

Dalam permainan Futsal pemain pasti mempunyai kekurangan, dan kekurangan itu sebagai tugas untuk pelatih agar bisa menutupi 
kekurangan tersebut. Dari hasil pelaksanaan tes awal terdapat dari hasil pelaksanan tes awal terdapat kekurangan pada pemain seperti cepat merasa lelah, rawan cidera, dan sulit memulihkan denyutnadi.

Sport Massage merupakan cara yang paling baik saat memulihkan kebugaran atlet futsal IKIP Mataram, bahkan bukang hanya atlet saja, orang-orang yang melakukan aktifitas yang beratpun bisa diberikan massage agar staminanya menjadi pulih, setelah diberikan massage pada atlet kebugarannya kembali pulih dan denyut nadi para atlet Futsal IKIP Mataram bisa pu;ih setelah diberikan Sport Massage.

Setelah melakukan penghitungan data penurunan denyut nadi recovery pada pemain futsal IKIP Mataram 2018 peneliti dapat mengetahui bahwasanya pemberian sport massage pada pemain futsal latihan dapat mempercepat pemulihan denyut nadi. Dari data diatas juga kita dapat mengetahui bahwa ada 2 atlet yang memiliki denyut nadi pemulihan dibawah 100 denyut permenit setelah diberikan sport massage, hal ini dapat dijadikan tolak ukur sport massage memiliki pengaruh yang sangat segnifikan terhadap penurunan denyut nadi recovery.

\section{SIMPULAN}

Berdasrkan pada analisa data dapat disimpulkan bahwa, dilihat dari hasil pemberian perlakuan sport massagethitung,4,603>1,860 t-tabel maka ada pengaruh Sport Massage terhadap penurunan denyut nadi recovery atlet Futsal IKIP Mataram 2018.

\section{SARAN}

Dari hasil penelitian dan analisa data bahwa didapat hasil maka, "Ada pengaruh Sport Massage terhadap penurunan denyut nadi recovery atlet Futsal IKIP Mataram 2018".Berdasarkan kenyataan tersebut adapun saran yang dapat peneliti berikan kepada atletFutsal IKIP Mataram, para pelatih atau pembina adalah "Untuk memperoleh kebugaran jasmani para pemain perlu diberikan sport massage kepada para atlet Futsal IKIP Mataram agar prestasi atlet bisa menjadi lebih baik lagi.

\section{DAFTAR PUSTAKA}

Andi Anshari, dan Yanuar. 2016. Efektifitas

Penurunan Denyut Nadi Pemulihan Dengan Pemberian Masase Tehnik

\section{Shaking Pada Atlet Futsal IKIP} Mataram.

Arikunto, Suharsimi. 2006. Prosedur Penelitian. Jakarta:Rineka Cipta.

Budi Purnomo. (2006). Pengaruh Pemberian Sport Massage Selama 10Menit pada Daerah Punggung terhadap Respons Cardio Vascular Orang Sehat. Skripsi. Yogyakarta:FIKUNY.

Darmadi, Hamid. 2013. Metode Penelitian Pendidikan. Bandung: Alfabeta.

Eko Budianto. (2005). Pengaruh Sport Massage Terhadap Tekanan Darah Dan Denyut Nadi Pada Tes Laril2 Menit Mahasiswa Ilmu Keolahrgaan Universitas Negeri Yogyakarta.Skripsi. Yogyakarta: FIKUNY.

Hulfian, Lalu. 2014. Statistik Dikjas. Mataram :Genius.

Hulfian, Lalu. 2014. Penelitian Dikjas. Mataram :CV. Garuda Ilmu.

Irenne, Elly. 2006. Perubahan Denyut Nadi Mahasiswa Setelah Aktivitas Naik Turun Tangga. Semarang :Universitas Diponegoro. Diakses dari eprints.undip.ac.id/20417/1/Irenne.pdf.

Pada Tanggal11 November 2016 pukul 16.45 .

Janssen, Peter G. J. M. 1993. Latihan Laktat Denyut Nadi (diterjemahkan oleh Peni K.S Mutalib). Jakarta: PT Pustaka Utama Grafiti.

Komunitas Relawan Independen. 2014. Denyut Nadi. Diakses Tanggal11 November 2016 Pukul 17.10.

Kusnanik, N.W., Nasution, J. and Hartono, S. 2011. Dasar-Dasar Fisiologi Olahraga. Unesa University Press.

Maksum, Ali. 2009. Statistika Dalam Olahraga. Unesa University Press. Priyonoadi, Bambang. 2008. Sport Massage. Yogyakarta :Fakultas Ilmu Keolagragaan Universitas Negeri Yogyakarta.

Purnomo, Budi. 2006. Pengaruh Pemberian Massage Selama 10 Menit Pada Daerah Punggung Terhadap Respons Cardiovascular Orang Sehat. Skripsi. Yogyakarta:FIK UNY.

Roepajadi, Joesoef. 2009. Masase Olahraga. Fakultas Ilmu Keolahragaan Universitas Negeri Surabaya. 
Sajoto. 1988. Pembinaan Kondisi Fisik Dalam Olahraga. Jakarta:Departemen Pendidikan dan Kebudayaan Direktorat Jenderal Pendidikan Tinggi Proyek Penggembangan Lembaga pendidikan Tenaga Kependidikan.

Setijono, Matuan kota, dan Hasan, 2001. Instruktur Fitness. Unesa University Press.

Soemardiawan., dan Mujriah. 2014. Massage Sport Segment. Mataram :Genius. Sugiyono. 2006. Statistik Untuk Penelitian. Bandung: Alfabeta.

Soemardiawan dan Lalu Srimukhlisin Wijaya, MH, 2016. Mempraktikkan Tehnik Dasar Futsal Moderen 2016. Selong: Garuda Ilmu.

Thompson,Walter R. 2008. ACSM's HealthRelated Physical Fitnes Assesment Manual. American Collegeof Sport medicine.

Tim Penyusun, 2011. Pedoman Penulisan Skripsi. IKIP Mataram.

Yanuar, Arif M. 2012. PengaruhPembebanan Latihan Pada Denyut Nadi Terhadap Konsentrasi Atlet Bulutangkis Pusdiklat Citra Raya Unesa. Tesis S2. Universitas Negeri Surabaya. 